\title{
Citizens and Air Quality: The Results of the First Survey Carried Out in the Po River Basin (Northern Italy)
}

\author{
Enrico Cancila ${ }^{1}$, Irene Sabbadini' ${ }^{1}$ Marco Ottolenghi' ${ }^{1}$, Marco Deserti², Sara Tessitore ${ }^{3}$ \\ ${ }^{1}$ ART-ER Attrattività Ricerca Territorio, Bologna, Italy \\ ${ }^{2}$ Regione Emilia-Romagna, Bologna, Italy \\ ${ }^{3}$ Sant'Anna Scuola Universitaria Superiore Pisa, Pisa, Italy \\ Email: marco.ottolenghi@art-er.it
}

How to cite this paper: Cancila, E., Sabbadini, I., Ottolenghi, M., Deserti, M. and Tessitore, S. (2019) Citizens and Air Quality: The Results of the First Survey Carried Out in the Po River Basin (Northern Italy). Open Journal of Air Pollution, 8, 69-79. https://doi.org/10.4236/ojap.2019.83003

Received: July 3, 2019

Accepted: September 16, 2019

Published: September 19, 2019

Copyright $\odot 2019$ by author(s) and Scientific Research Publishing Inc. This work is licensed under the Creative Commons Attribution International License (CC BY 4.0).

http://creativecommons.org/licenses/by/4.0/

\begin{abstract}
The air quality survey investigated the level of perception and awareness of citizens on the air quality in the 42 cities (provincial capitals) of the Po basin in the north west of Italy. This study means that perceptions could then be compared between in the Po basin and other parts of Italy and Europe. This research was carried out as part of the Life15 IPE IT 013 PREPAIR Project (Po Regions Engaged to Policies of Air), which involves 18 national and international partners, and includes all the regions of the Po Basin. The survey involved around 7331 citizens that live in the Po basin that includes 42 cities (provincial capitals) and a total of 6.5 million inhabitants. A multivariate analysis was applied to identify the main citizens' profiles concerning the topic of air quality and the availability to implement virtuous behaviours to reduce air pollution. Four different profiles emerge from the cluster analysis: "Committed and proactive", "Willing but ...", "Hesitant", "Not willing".
\end{abstract}

\section{Keywords}

Perception, Air, Pollution, Quality Citizens

\section{Introduction}

Air pollution is a key environmental and social issue and, at the same time, it is a complex problem posing multiple challenges in terms of management and mitigation of harmful pollutants. Air pollutants are emitted from anthropogenic and natural sources; they may be either emitted directly (primary pollutants) or formed inthe atmosphere (as secondary pollutants). 
Air quality is a major concern for Europeans, and is an area where the EU has been particularly active for more than 30 years. The EU's key objective in relation to air quality is "to achieve levels of air quality that do not result in unacceptable impacts on, and risks to, human health and the environment". The EU has already in place a range of legislation and initiatives to improve air quality by controlling harmful emissions and implementing measures in the transport, industry and energy sectors to protect the environment. In addition, air pollution is one of the key issues included as part of the European Commission's proposal for a new Environment Action Programme (EAP) to 2020, "Living well, within the limits of our planet". A survey by European Commission demonstrates that $56 \%$ of Europeans think air quality has deteriorated in the last 10 years, and $16 \%$ say it has improved. Emissions from cars and trucks (96\%) and emissions from industrial production and fossil fuel power stations (92\%) are the most likely to be mentioned as having an impact.

Air quality policies have delivered, and continue to deliver, many improvements. Reduced emissions have improved air quality in Europe, and, for a number of pollutants, exceedances of European standards are rare. However, substantial challenges remain and considerable impacts on human health and on the environment persist. Despite the improvements, a large proportion of European populations and ecosystems are still exposed to air pollution that exceeds European standards and, especially, the World Health Organization (WHO) Air Quality Guidelines (AQGs).

Effective air quality policies require action and cooperation at global, European, national and local levels, which must reach across most economic sectors and engage the public. Holistic solutions must be found that involve technological development and structural and behavioural changes. The aim of the European project PREPAIR is promoting sustainable lifestyles, production and consumption, that is, capable of affecting emissions reduction. To do this, specific awareness-raising and dissemination actions are planned for public, private and local communities.

\section{Background}

Air pollution is a substantial problem that continues to threaten public health and contributes to climate change. Pollutants such as particulate matter with an aerodynamic diameter smaller than $2.5 \mu \mathrm{m}$ (PM2.5), nitrogen oxides $\left(\mathrm{NO}_{\mathrm{x}}\right.$ ), and tropospheric ozone $\left(\mathrm{O}_{3}\right)$ continue to be a cause of cancer, respiratory and cardiovascular disease, and premature death (EEA, 2016). Poor air quality is detrimental to human health, with a number of studies finding short-term and long-term pulmonary and cardiovascular health effects of PM10 and PM2.5 [1]. Two main pollutants are considered key indicators of ambient, or outdoor, air quality: fine particle pollution-airborne particulate matter measuring less than 2.5 micrometers in aerodynamic diameter, commonly referred to as PM2.5 and ground-level (tropospheric) ozone [2]. 
The Air quality report in 2017 demonstrated that air quality policies have delivered, and continue to deliver, many improvements. Reduced emissions have improved air quality in Europe, and, for a number of pollutants, exceedances of European standards are rare [3].

Air pollution also incurs major economic costs to the European Union, on the order of billions of Euros a year (EEA, 2016).

In developed countries, trends of urbanization and the associated growth of cities have started to reverse due to severe levels of congestion [4] However, in developing countries, city's growth tends to be from periphery to core. The ambient air pollution levels at urban hot spots in 20 European cities have exceeded the urban background concentrations due to increase in traffic volume (Moussiopoulos et al., 2005) [5]. In the UK, motorized road transport has been categorized as one of the largest single pollution sources in $92 \%$ of declared air quality management areas which accounts for $33 \%$ emissions of NOX and $21 \%$ of PM10, and so, frequently violating the national ambient air quality standards/objectives (Faulkner and Russell, 2010) [6]. However, in the recent past, it has been observed that in some mega cities of developed countries, urban air quality is showing signs of improvement on account of efficient implement action of UAQMP (NSW Government, 2010; EEA, 2011a; Parrish et al., 2011; EEA, 2013a) [7] [8]. In the European Environment Agency (EEA) countries, the emission reduction from vehicular exhausts from 1990 to 2009 has been reported to be around $54 \%$ for $\mathrm{SO}_{2}, 27 \%$ for $\mathrm{NO}_{\mathrm{X}}, 16 \%$ for PM10 and $21 \%$ for PM2.5. In spite of all these efforts in place, it has been observed that $18 \%$ to $49 \%$ of the population in these countries is still exposed to PM10 concentrations exceeding the ambient standard [9] [10].

In the last two decades, a variety of studies have been conducted investigating the perceptions of air quality in cities all around the world. Sociodemographic factors such as age, gender, education, and health status have been found to be correlated with perceptions of air quality (Oltra \& Sala, 2014) [11]. Guo et al. (2016) [12] found that, in their sample, those respondents over the age of 40 , with a college-level education, living in an urban residential area, or with a child in poor health condition were more likely to perceive the air quality to be poor. Several studies have found women to be more likely to acknowledge that air pollution will lead to adverse health effects or to perceive the air quality as poor compared with men [13] [14]. In addition, evidence suggests that racial/ethnic minorities and low socioeconomic status populations are disproportionately exposed to certain air pollutants [15] [16]. Disparities in exposure to air pollutants may contribute to racial/ethnic and socioeconomic disparities in adverse health outcomes associated with air pollution exposure [17] [18] [19].

Beyond the direct consequences for human health of air pollution exposure, it is also important to consider public perceptions of air pollution, which may influence behavioral and lifestyle choices that have a direct impact on health and well-being. Public perceptions about air pollution and the associated health risk concerns are influenced by three primary factors: psychological makeup of indi- 
viduals; social characteristics of individuals; and environmental conditions in which individuals live, including pollution exposure [20] [21] [22]. Two elements of psychological makeup that influence pollution perceptions and health concerns are knowledge and self-efficacy. Knowledge, or awareness, of air quality amplifies an individual's perception of risk, while self-efficacy is an individual's confidence that they can perform a task to address a given situation, for instance, the ability to personally do something to improve air quality [23]. Some studies have observed associations between public perceptions of air quality and pollution exposure (i.e. residents of areas with higher pollution levels perceived poorer air quality) [20] [21] [22] [23], while others do not [21].

\section{Method and Research Objective}

The objective of this cluster analysis was to bring the 7331 citizens interviewed back to a limited number of groups so as to be able to trace the prevailing profiles and the related trends on the topic of air quality and its possible improvement. The analysis was therefore aimed at detecting similarities and significant differences between the respondents in terms of:

- perception of air quality,

- areas where the challenges on the subject can best be addressed,

- sources of information,

- behaviors and initiatives to be implemented to improve air quality.

These aspects were investigated through 9 variables, which made it possible to distinguish the clusters within the survey sample. Of these variables 3 they consist of questions included in the questionnaire, while 6 variables have been constructed to measure certain behavior trends among the sample. The survey was online. A questionnaire is composed by four sections that allow to investigate the items cited above:

- the assessment of air quality,

- perception on air quality,

- actions to reduce air pollution,

- profile on inhabitant.

Following the main phases of the research method:

1) Survey and data collection,

2) Qualitative data processing,

3) Factorial analysis.

a) The survey took place from 23 November 2018 to 10 January 2019 and aroused great interest in the entire area of the Po basin. 7331 citizens voluntarily filled in the questionnaire.

The 3 questions presented in the questionnaire and used as variables in the cluster analysis were the following:

- Over the past 10 years, how has air quality changed?

- Where can the challenges posed by the issue of air quality be better addressed?

- What are the main sources from which you receive information on air quali- 
ty in your city?

b) Collected data were processed to define the perception of air quality among north Italian citizens. The main topic investigated are:

- the assessment of air quality,

- perception on air quality,

- actions to reduce air pollution,

- profile on inhabitant.

c) Appling a factorial analysis to some questions of questionnaire section 3 and 4 emerge four dimensions to fill in the cluster analysis. These dimensions emerged processing the 17 questions that made up these two questionnaire sections, through a factorial analysis carried out with a software for statistical processing (STATA 15). The factorial analysis can be generically thought of as the search for latent variables starting from some observed variables. This technique makes it possible to highlight the existence of factors or dimensions, not directly measurable, within a set of variables. Factor analysis is a way to take a mass of data and shrinking it to a smaller data set that is more manageable and more understandable. It's a way to find hidden patterns, show how those patterns overlap and show what characteristics are seen in multiple patterns. It is also used to create a set of variables for similar items in the set.

Based on these variables and dimensions a cluster analysis is processed by $\mathrm{A}$ non-hierarchical method generates a classification by partitioning a dataset, giving a set of (generally) non-overlapping groups having no hierarchical relationships between them.

Table 1 shows the combined questions to develop the new 4 dimensions.

\section{Sample Description}

The survey took place from 23 November 2018 to 10 January 2019 and aroused great interest in the entire area of the Po basin. A total of 7331 citizens voluntarily filled in the questionnaire ensuring a representativeness of $36.3 \%$ compared to the total number of municipalities that make up this area and $77 \%$ of the population that is resident (4188 municipalities, with a population of 25.1 million people). All 42 cities (provincial capitals) in the basin were involved, where a total of 6.5 million inhabitants live, equal to $26 \%$ of the total population of the area.

The majority of sample lives in the urban centers of the plain: the percentage of respondents living in the countryside is only $11.6 \%$, while $33.3 \%$ live in the center and $55.1 \%$ in the first belt periphery. We find that around three quarters of the respondents reside in the plains, $19.7 \%$ in the hills and $4.6 \%$ in the mountains. Table 2 shows the others sample features (see Table 2).

\section{Results}

Citizens of the Po basin perceive the air quality as deteriorating. The real data, however, show that in Europe emissions of the main pollutants have actually 
Table 1. New dimensions emerged from factor analysis.

\begin{tabular}{|c|c|c|c|}
\hline Main Question & Sub questions & Answers & Emerged dimension \\
\hline \multirow{6}{*}{$\begin{array}{l}\text { Which of the following } \\
\text { behaviors would you be } \\
\text { willing to implement to } \\
\text { reduce air pollution? }\end{array}$} & $\begin{array}{l}\text { Prefer the use of public transport } \\
\text { Use the bicycle when possible }\end{array}$ & $\begin{array}{l}\text { Yes, } \\
\text { yes under certain conditions } \\
\text { No I would not be available }\end{array}$ & $\begin{array}{l}\text { Sustainability in private } \\
\text { transport }\end{array}$ \\
\hline & $\begin{array}{l}\text { Choose hybrid/electric vehicles } \\
\text { Buy appliances with low consumption/high efficiency/ } \\
\text { low emissions }\end{array}$ & $\begin{array}{l}\text { Yes, } \\
\text { yes under certain conditions } \\
\text { No I would not be available }\end{array}$ & $\begin{array}{l}\text { Buy efficiently and } \\
\text { sustainably }\end{array}$ \\
\hline & $\begin{array}{l}\text { Limit the use of air conditioners at home/work } \\
\text { Lower home temperature }\end{array}$ & $\begin{array}{l}\text { Yes, } \\
\text { yes under certain conditions, } \\
\text { No I would not be available }\end{array}$ & $\begin{array}{l}\text { Adopt behaviors that } \\
\text { support the energy } \\
\text { efficiency }\end{array}$ \\
\hline & Buy local products & & \\
\hline & $\begin{array}{l}\text { Collect information about air quality, follow suggested } \\
\text { good practices }\end{array}$ & $\begin{array}{l}\text { Yes, } \\
\text { yes under certain conditions, } \\
\text { No I would not be available }\end{array}$ & $\begin{array}{l}\text { Adopt behaviors for } \\
\text { social reasonability and } \\
\text { environmental friendly }\end{array}$ \\
\hline & Raise awareness through volunteering/civic initiatives & & \\
\hline \multirow{4}{*}{$\begin{array}{l}\text { Your opinion concerning } \\
\text { the following initiatives }\end{array}$} & Limit to circulation in urban areas and controls & & \\
\hline & $\begin{array}{l}\text { Establishment and/or extension of ZTL/pedestrian areas } \\
\text { Prohibition of circulation of private heavy vehicles } \\
\text { in urban areas }\end{array}$ & $\begin{array}{l}\text { Favorable, favorable to certain } \\
\text { conditions, contrary }\end{array}$ & Sustainable mobility \\
\hline & Modal shift towards cycle-pedestrian mobility & & \\
\hline & $\begin{array}{l}\text { Domestic biomass heating limitation } \\
\text { Greater regulation on boiler use }\end{array}$ & $\begin{array}{l}\text { Favorable, favorable to certain } \\
\text { conditions, contrary }\end{array}$ & Better heating efficiency \\
\hline
\end{tabular}

Table 2. Sample description.

\begin{tabular}{|c|c|c|c|}
\hline \multirow[t]{2}{*}{ Variable } & & \multicolumn{2}{|l|}{ distribution } \\
\hline & & Number of peoplecomposed the sample & $\%$ \\
\hline \multirow{8}{*}{ Region } & Piedmont & 1.212 & $17 \%$ \\
\hline & Valle d'Aosta & 202 & $3 \%$ \\
\hline & Lombardy & 1.810 & $25 \%$ \\
\hline & Trento & 370 & $5 \%$ \\
\hline & Veneto & 1.634 & $22 \%$ \\
\hline & Friuli Venezia Giulia & 517 & $7 \%$ \\
\hline & Emilia Romagna & 1.586 & $22 \%$ \\
\hline & Total & 7.331 & $100 \%$ \\
\hline \multirow{5}{*}{ Age } & 20 - 39 years old & 2.813 & $38 \%$ \\
\hline & $40-64$ years old & 3.091 & $42 \%$ \\
\hline & $65+$ years old & 739 & $10 \%$ \\
\hline & n.d. & 688 & $9 \%$ \\
\hline & Totale & 7.331 & $100 \%$ \\
\hline \multirow{4}{*}{ Gender } & Female & 2.716 & $37 \%$ \\
\hline & Male & 3.838 & $52 \%$ \\
\hline & n.d. & 777 & $11 \%$ \\
\hline & Total & 7.331 & $100 \%$ \\
\hline
\end{tabular}


decreased. The perception of air quality is negative both in the Po basin, Italy and Europe, highlighting that citizens seem to be more influenced by pre-conceived than any awareness based on up-to-date information.

The survey opened with a question on the "perception of air quality trends over the past 10 years". $63.3 \%$ of respondents said that it has deteriorated, $22.6 \%$ think it has remained the same, while $6.3 \%$ say it has improved.

Citizens appear to derive their main source of information on air quality from the Internet and social media (a total of $66.2 \%$ of respondents), but the respondents still use traditional sources such as TV and newspapers. However, although it is easier to reach citizens via the Internet, there is a risk of "fake news". In the Po basin there is the perception that local administrations can improve the air quality more efficiently than Italian and European institutions. Given that promoting a change in people's lifestyles is one of the essential elements for air quality policies, this element of "empowerment" is even more interesting. Furthermore, the citizens of the Po basin see intervening in industrial processes as a priority, but only $11.1 \%$ of the sample consider traffic restrictions as an important means for reducing pollution and traffic in reality is a primary cause of pollution $(59.8 \%)$. The survey on the willingness of citizens to put into practice behaviors and actions to improve air quality is very interesting; in particular, the percentage surveyed on the basis of limited availability reveals a sort of distrust in the implementation of certain behaviors that are required of citizens.

Public transport with $48.1 \%$ of conditional approval is an obvious reminder of the need to improve the service. Hybrid electric vehicles, in turn, with a conditional availability of $44.2 \%$ and the purchase price are still considered to be too high.

The multivariate analysis highlighted four clusters of citizens divided on the basis of proactivity/availability to implement virtuous behaviours to improve air quality: "Committed and proactive", "Willing but ...", "Hesitant", "Not willing”.

To stimulate a change in the lifestyles of large sections of the population, precise strategies must be adopted and there should be a clear "pact" where each actor plays their part according to their own resources and capacities.

The target of a communication campaign could be to raise the current percentage of $16 \%$ of citizens currently "committed and proactive" to $36 \%$ (thus affecting the $20 \%$ who are "wiling, but ...").

On the other hand, involving up to 68 (including the $32 \%$ "hesitant"), would be much more demanding and in this case the communication campaign should be accompanied with other improvement policies such improving the efficiency of local services as well as air quality policies in general. The "unavailable" remain instead a significant and perhaps intangible hard core, if not through compulsory policies or at least a joint effort by all the actors.

It is also clear that the cost of the actions will probably be incremental and proportional to the level of involvement that an individual citizen wishes to achieve and consequently, in a cost-benefit analysis, it might be useful to focus on a target that can be reached, for example by mainly influencing the "willing 
but ..." group and giving up on the idea of trying to influence the "unwilling".

Using many of the variables used to isolate our five "events", a cluster analysis was carried out which made it possible to identify the prevailing profiles of citizens with respect to the issue of air quality. A cluster analysis is a statistical technique that identifies groups of units similar to each other with respect to a set of variables. The objective of this cluster analysis was to classify the 7331 respondents into a limited number of groups so as to be able to reveal the prevailing profiles. The analysis was therefore aimed at detecting similarities and significant differences between the respondents in terms of:

- perception of air quality,

- areas where the challenges can best be addressed,

- sources of information,

- behaviors and initiatives to be implemented to improve air quality.

These aspects were investigated through nine variables leading to the classification of four groups on the basis of their commitment to reducing air pollution. In fact, the study confirms that citizens tend to be more proactive when they are asked to put into practice virtuous behaviors and initiatives that could affect the quality of the air making it better.

Based on the values of the nine variables selected, four citizen profiles were identified (Table 3):

- Engaged and proactive: very willing to implement virtuous behaviors to improve air quality;

- Available, but ...: quite willing to implement virtuous behaviors;

- Hesitant: generally unwilling to implement virtuous behaviors.

Not willing: very low level of willingness to implement virtuous behaviors.

A detailed analysis of the four clusters reveals some substantial differences:

1) Engaged and proactive. This is the least numerous cluster (16\%), representing those citizens who are most willing to engage in the improvement of air quality. They generally feel that it is up to EU institutions to tackle the challenges of improving air quality. These citizens are willing to invest in sustainable mobility, responsible behaviour and promotion of sustainability even in their most private sphere such as the use of private transport and the efficiency of heating.

2) Available, but ... The citizens that make up this cluster (20\%) are slightly more worried about air quality than those in the "Engaged and proactive" cluster and see supra-regional and regional institutions as the actors who should do more to achieve the goals.

The cluster is composed of citizens who show that they want to commit themselves, albeit in a generic way, without identifying with determination the behaviors and initiatives to be implemented.

3) Hesitant. This cluster brings together citizens who show little willingness to act to improve air quality. These citizens see the European institutions as the actors who should do more to improve air quality. Although this group is more concerned about the quality of the air than those of the other clusters they are not willing to engage in the initiatives and in the proposed behaviours, particu- 
larly sustainable mobility.

4) Not willing. There is no commitment to improving air quality by the citizens in this cluster, which is unfortunately the most numerous even though they perceive a continuously deteriorating quality of the air. The citizens of this cluster are essentially unwilling to engage in any the proposed activities particularly sustainable mobility such as traffic free zones (resident traffic only), traffic restrictions etc. (Table 4).

\section{Conclusions}

There is clear that there are many considerations that could be made and for these we refer to the investigation document in its entirety. Interestingly, some (though not the majority) citizens of the Po basin already appear to be willing to change their lifestyles. To achieve real change, the unity of purpose and clarity with which actions and proposals are presented to citizens appear to be key elements. Even the most responsible and aware citizens, in fact, assesses how much they are subjected not only in terms of technical information but also through their own emotional sphere. The greater the transparency of the process and the commitment of the parties involved, the greater the effectiveness of communication policies is.

Table 3. Classification and number of the four clusters.

\begin{tabular}{|c|c|c|}
\hline \multicolumn{3}{|c|}{ Clusters } \\
\hline Citizen profile & Description of profile & $\%$ of each cluster \\
\hline Engaged and proactive & Citizens who want to take action and encourage others to take action to improve air quality & $16 \%$ \\
\hline Available but & Citizens willing to do something to improve the current situation & $20 \%$ \\
\hline Hesitant & The situation is getting worse but I am unwilling to do much to change the situation & $31 \%$ \\
\hline Not available & Although the situation is getting worse, I don't care & $33 \%$ \\
\hline
\end{tabular}

Table 4. Clusteranalysis results.

\begin{tabular}{|c|c|c|c|c|c|c|c|c|c|c|c|c|c|c|}
\hline \multirow[b]{2}{*}{ Cluster } & \multicolumn{14}{|c|}{ Variables and dimensions } \\
\hline & $\begin{array}{c}\text { Air } \\
\text { quality } \\
\text { perception } \\
\text { in the last } \\
\text { ten years }\end{array}$ & $\begin{array}{c}\text { Institutional } \\
\text { level that } \\
\text { should } \\
\text { improve air } \\
\text { quality }\end{array}$ & web & newspaper & $\begin{array}{c}\text { Mobile } \\
\text { application }\end{array}$ & radio & $\mathrm{TV}$ & $\begin{array}{c}\text { Social } \\
\text { network }\end{array}$ & $\begin{array}{l}\text { Sustainability } \\
\text { in private } \\
\text { transport }\end{array}$ & $\begin{array}{l}\text { Buy } \\
\text { efficiently } \\
\text { and } \\
\text { sustainably }\end{array}$ & $\begin{array}{c}\text { Adopt } \\
\text { behaviors } \\
\text { that } \\
\text { support } \\
\text { the energy } \\
\text { efficiency }\end{array}$ & $\begin{array}{c}\text { Adopt } \\
\text { behaviors for } \\
\text { social } \\
\text { reasonability } \\
\text { and } \\
\text { environmental } \\
\text { friendly }\end{array}$ & $\begin{array}{c}\text { Sustainable } \\
\text { mobility }\end{array}$ & $\begin{array}{c}\text { Better } \\
\text { heating } \\
\text { efficiency }\end{array}$ \\
\hline $\begin{array}{l}\text { Engaged } \\
\text { and } \\
\text { proactive }\end{array}$ & 2.49 & 1.54 & 0.42 & 0.28 & 0.07 & 0.07 & 0.34 & 0.24 & 0.74 & 0.35 & 0.35 & 0.91 & 0.99 & 0.67 \\
\hline $\begin{array}{c}\text { Available } \\
\text { but ... }\end{array}$ & 2.54 & 3.85 & 0.45 & 0.27 & 0.08 & 0.09 & 0.29 & 0.28 & 0.44 & 0.48 & 0.39 & 0.42 & 0.60 & 0.67 \\
\hline Hesitant & 2.62 & 1.30 & 0.49 & 0.30 & 0.07 & 0.11 & 0.29 & 0.26 & -0.29 & -0.25 & -0.32 & -0.38 & -0.40 & -0.31 \\
\hline $\begin{array}{c}\text { Not } \\
\text { available }\end{array}$ & 2.65 & 3.81 & 0.50 & 0.30 & 0.08 & 0.10 & 0.23 & 0.28 & -0.34 & -0.26 & -0.36 & -0.41 & -0.48 & -0.45 \\
\hline
\end{tabular}


This survey could be repeated in the future with a sample representative of the Italian population. Possible comparisons can be developed between the Po basin sample and the remains of Italy and of Europe samples. In addition, longitudinal studies could be developed to measure the changes in the air perception among Italian and Po basin inhabitants.

\section{Conflicts of Interest}

The authors declare no conflicts of interest regarding the publication of this paper.

\section{References}

[1] Rückerl, R., Schneider, A., Breitner, S., Cyrys, J. and Peters, A. (2011) Health Effects of Particulate Air Pollution: A Review of Epidemiological Evidence. Inhalation toxicology, 23, 555-592. https://doi.org/10.3109/08958378.2011.593587

[2] Health Effects Institute (2019) State of Global Air 2019. Special Report. Health Effects Institute, Boston, MA.

[3] EEA (European Environment Agency) (2017) Air Quality in Europe-Report 2017.

[4] Mayer, H. (1999) Air Pollution in Cities. Atmospheric Environment, 33, 4029-4037.

[5] Moussiopoulos, N., Vlachokostas, C., Tsilingiridis, G., Douros, I., Hourdakis, E., Naneris, C. and Sidiropoulos, C. (2009) Air Quality Status in Greater Thessaloniki Area and the Emission Reductions Needed for Attaining the EU Air Quality Legislation. Science of the Total Environment, 407, 1268-1285.

[6] Faulkner, M. and Russell, P. (2010) Review of Local Air Quality Management. A Report to Defra and the Devolved Administrations, 98.

[7] Parrish, D.D., Singh, H.B., Molina, L. and Madronich, S. (2011) Air Quality Progress in North American Megacities: A Review. Atmospheric Environment, 45, 7015-7025. https://doi.org/10.1016/j.atmosenv.2011.09.039

[8] EC (European Commission) (2011) European Commission Environment-Air Quality. http://ec.europa.eu/environment/air/quality/legislation/assessment.htm

[9] EEA (European Environment Agency) (2016) Climate Change, Impacts and Vulnerability in Europe 2016. EEA Report No 1/2017.

[10] EEA (European Environment Agency) (2013) Air Quality in Europe-2013, EEA Technical Reports 9/2013, Copenhagen, $112 \mathrm{p}$.

[11] Oltra, C. and Sala, R. (2014) A Review of the Social Research on Public Perception and Engagement Practices in Urban Air Pollution (No. CIEMAT-1317). Centro de Investigaciones Energeticas Medioambientales y Tecnologicas (CIEMAT).

[12] Guo, J., He, J., Liu, H., Miao, Y., Liu, H. and Zhai, P. (2016) Impact of Various Emission Control Schemes on Air Quality Using WRF-Chem during APEC China 2014. Atmospheric Environment, 140, 311-319.

[13] Elliott, S.J., Cole, D.C., Krueger, P., Voorberg, N. and Wakefield, S. (1999) The Power of Perception: Health Risk Attributed to Air Pollution in an Urban Industrial Neighbourhood. Risk Analysis, 19, 621-634. https://doi.org/10.1111/j.1539-6924.1999.tb00433.x

[14] Howel, D., Moffatt, S., Bush, J., Dunn, C.E. and Prince, H. (2003) Public Views on the Links between Air Pollution and Health in Northeast England. Environmental Research, 91, 163-171. 
[15] Miranda, M.L., Edwards, S.E., Keating, M.H. and Paul, C.J. (2011) Making the Environmental Justice Grade: The Relative Burden of Air Pollution Exposure in the United States. International Journal of Environmental Research and Public Health, 8, 1755-1771. https://doi.org/10.3390/ijerph8061755

[16] Bell, M.L., Ebisu, K. and Belanger, K. (2007) Ambient Air Pollution and Low Birth Weight in Connecticut and Massachusetts. Environmental Health Perspectives, 115, 1118-1124.

[17] Watson, B.R., Riffe, D., Smithson-Stanley, L. and Ogilvie, E. (2013) Mass Media and Perceived and Objective Environmental Risk: Race and Place of Residence. Howard Journal of Communications, 24, 134-153.

[18] Nachman, K.E. and Parker, J.D. (2012) Exposures to Fine Particulate Air Pollution and Respiratory Outcomes in Adults Using Two National Datasets: A Cross-Sectional Study. Environmental Health, 11, 25. https://doi.org/10.1186/1476-069X-11-25

[19] Apelberg, B.J., Buckley, T.J. and White, R.H. (2005) Socioeconomic and Racial Disparities in Cancer Risk from Air Toxics in Maryland. Environmental Health Perspectives, 113, 693-699. https://doi.org/10.1289/ehp.7609

[20] Coi, A., Minichilli, F., Bustaffa, E., Carone, S., Santoro, M., Bianchi, F. and Cori, L. (2016) Risk Perception and Access to Environmental Information in Four Areas in Italy Affected by Natural or Anthropogenic Pollution. Environmental Health Perspectives, 95, 8-15. https://doi.org/10.1016/j.envint.2016.07.009

[21] Claeson, A.S., Lidén, E., Nordin, M. and Nordin, S. (2013) The Role of Perceived Pollution and Health Risk Perception in Annoyance and Health Symptoms: A Population-Based Study of Odorous Air Pollution. International Archives of Occupational and Environmental Health, 86, 367-374. https://doi.org/10.1007/s00420-012-0770-8

[22] Brody, S.D., Peck, B.M. and Highfield, W.E. (2004) Examining Localized Patterns of Air Quality Perception in Texas: A Spatial and Statistical Analysis. Risk Analysis. An International Journal, 24, 1561-1574. https://doi.org/10.1111/j.0272-4332.2004.00550.x

[23] Cutter, S.C. (1981) Community Concern for Pollution: Social and Environmental Influences. Environment and Behavior, 13, 105-124.

https://doi.org/10.1177/0013916581131006 